- The Orthodontic teaching syllabus in UK dental schools, as prescribed by Paragraph 95 of the GDC document The First Five Years, may be inappropriate to the present day.

- Surveys have been carried out to assess the time, allocations and structures of orthodontic courses in UK dental schools.

- Students have good levels of basic orthodontic knowledge but are less successful when asked to apply that knowledge to clinical situations.

- Three quarters of dental schools believe that it is unrealistic to expect graduating dental students to be able to formulate orthodontic treatment plans.

\title{
Orthodontic teaching practice and undergraduate knowledge in British dental schools
}

\author{
W. P. Rock, ${ }^{1}$ K. D. O'Brien ${ }^{2}$ and C.D. Stephens ${ }^{3}$
}

\begin{abstract}
Aim: The aim was to survey current orthodontic teaching practice in the undergraduate syllabus at British dental schools and to test the abilities of undergraduate students according to the requirements of the GDC regulations.

Materials and methods: Information collected by means of a questionnaire sent to each dental school in 1998 was compared with similar data from 1994. The orthodontic knowledge and treatment planning ability of students was assessed by a multiple-choice examination paper completed by a random $10 \%$ sample of students from each dental school.

Results: In 1998 on average 195 curriculum hours were devoted to orthodontics and each student treated five patients. The teaching of fixed appliances had increased considerably between 1994 and 1998. The average MCQ score was 58\% (range 39-72\%). Students scored well on questions that tested basic knowledge but much less well when they were required to apply that knowledge. Only three schools felt that it was realistic to expect undergraduates to formulate orthodontic treatment plans, as they are required to do by the GDC.
\end{abstract}

Conclusion: Results support the view that undergraduate orthodontic training should concentrate on diagnosis and recognition of problems rather than on providing limited exposure to treatment techniques.

In recent years there has been a growing feeling amongst academic staff in orthodontic units that Section 95 of the General Dental Council document The First Five Years is unrealistic in some of its expectations. The full text of the relevant paragraph is produced below:

'Orthodontics is concerned with the extent of normal variation of form and function of both the hard and soft tissues of mouth and face, and particularly in the way in which such variations produce differences of occlusion. The study of these factors should emphasise their inter-relationships with the general

\footnotetext{
${ }^{1 *}$ Reader in Orthodontics, School of Dentistry, St Chads Queensway, Birmingham, B4 6NN; ${ }^{2}$ Professor of Orthodontics, University Dental Hospital of Manchester, Higher Cambridge Street, Manchester, M15 6FH; ${ }^{3}$ Professor of Orthodontics, School of Dentistry, Lower Maudlin Street, Bristol, BS1 2LY

Correspondence to: W. P. Rock

E-mail:W.P.Rock@bham.ac.uk
}

\section{Refereed Paper}

Received 6.7.00; Accepted 23.11.00

$\odot$ British Dental Journal 2002; 192: 347-351 growth and development of the individual and be related to social and psychological factors and common disease processes. A major objective is that the student should be able to apply the principles of orthodontics in general practice and to recognise the limitations that exist in that situation. That involves the ability to carry out diagnostic procedures, formulate treatment plans and relate them to comprehensive patient care. It also means that the student should observe the complete treatment of some orthodontic cases and understand the significance of the events which take place. Students should carry out the continuing care of patients requiring simple appliance therapy. Teaching should also indicate the important of the orthodontic needs of adult patients'.

The main concern expressed by members of the University Teachers' Group (UTG) of the British Orthodontic Society has been that it may be unrealistic to expect new graduates to have sufficient orthodontic experience and competence to permit them to formulate treatment plans.

The aims of the present studies were:

- To survey current orthodontic teaching practice in the undergraduate syllabus at British dental schools.

- To gather information as to the expectations of teachers of orthodontics concerning newly qualifying graduates.

- To test the orthodontic knowledge and competence of a sample of final year students by means of a treatment planning exercise.

\section{MATERIALS AND METHODS}

In 1994 the UTG carried out a survey of orthodontic teaching practice in the undergraduate syllabus at British dental schools. A questionnaire was sent to the Head of Orthodontics in each school asking for information concerning the time allocated to orthodontic teaching. Time was calculated on the basis of one half day being 
counted as 3 hours. Other questions were asked concerning the amount and type of clinical experience provided to students and the perceptions of teachers concerning the competence of their new graduates with various techniques.

During the summer of 1998 the survey was repeated in a similar but rather more extended format. Course directors were asked to estimate the level of competence of their students in the use of different types of appliance according to a five-point scale on which $0=$ total incompetence and $5=$ full competence. To obtain opinions concerning Section 95 of The First Five Years, ${ }^{1}$ respondents were asked to indicate whether each of six statements derived from the GDC recommendations was realistic or unrealistic.

When the findings of the 1998 survey had been analysed and compared with the 1994 results a second investigation was begun to test the orthodontic competence of a sample of final year undergraduates from dental schools throughout the United Kingdom. A questionnaire was produced based upon the records of ten cases, representing a range of malocclusions. Each case study consisted of a brief verbal outline illustrated by photographs of radiographs and study casts (Fig. 1). To ensure consistent quality the illustrations were not photocopied, instead they were all original digital prints produced using a high quality laser printer. Each case had been treated by an orthodontic specialist registrar and submitted as part of the M Orth examination. Both the diagnosis and treatment result had therefore been subjected to searching review. Questions and answers for the present study were set and agreed by the three authors, each of whom was head of an academic orthodontic unit. Before circulation the test was piloted amongst a group of undergraduate students who did not take part in the actual study. Several questions were modified in the light of this pilot.

Three questions were set in association with each case, to give a total of 30 questions, which were subdivided into the five broad categories of basic knowledge, understanding of aetiology, diagnosis, and extraction choices; although not every case included a question from each category. Appliance selection was considered under the headings of removable, functional, single arch and full fixed appliances. Case studies were bound into folders and sent to each of the 13 United Kingdom dental schools along with a covering letter requesting that the test was attempted by every tenth final year dental student according to the alphabetical register, plus the last student on the list. Folders were sent out in April 1999 and course directors were asked to present them under examination conditions to ensure uniformity.

Fig. 1 An example of a question. Correct answers are in bold type.

Sajid aged 20 years has a Class II Division 2 malocclusion. The $0 / \mathrm{J}$ is $2 \mathrm{~mm}$, the $\mathrm{O} / \mathrm{B}$ is complete to tooth. Molar relationship is slightly Class III on each side. There is mild upper and moderate lower incisor crowding.

Ceph values: SNA $81^{\circ} \mathrm{SNB} 77^{\circ} \mathrm{UIA} 98^{\circ} \mathrm{LIA} 95^{\circ} \mathrm{MMPA} 19^{\circ} \mathrm{LI}-\mathrm{APO} 0.5 \mathrm{~mm}$.

What will be the value of the inter-incisal angle?

a) $95^{\circ}$

b) $131^{\circ}$

c) $65^{\circ}$

d) $148^{\circ}$

e) $109^{\circ}$

What extractions would you advise in this case?

a) None

b) All second premolars

c) All first premolars

d) Upper second and lower third molars

e) Upper second and lower first premolars

\section{What type of appliance therapy would you advise?}

a) Proclination of upper central incisors, followed by a functional appliance

b) An upper removable appliance to retract canines and make space for lateral incisors

c) No appliance necessary

d) Upper and lower fixed appliances
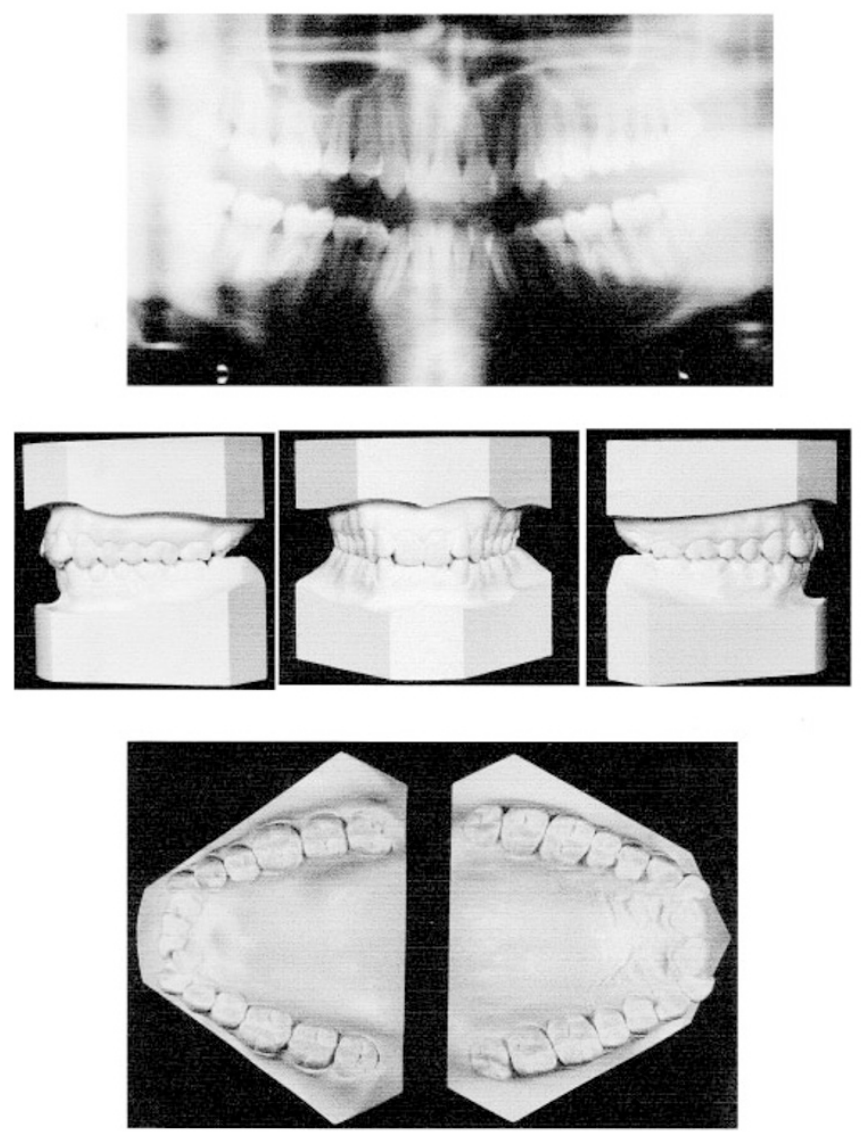
Table 1 Allocations of teaching time

\begin{tabular}{lrrrr}
\hline Course time & Mean & Range & Mean & Range \\
\hline Total Course (hours) & N/A & & 1998 & $109-286$ \\
Lectures (hours) & N/A & & 22 & $15-30$ \\
Seminars (hours) & 38 & $18-55$ & 35 & $21-59$ \\
CAL (hours) & & & N/A & $0-40$ \\
Laboratory Course (hours) & 33 & $4-80$ & 32 & $3-65$ \\
Clinical Work (hours) & 130 & $50-250$ & 97 & $54-184$ \\
Clinical period (months) & 24 & $12-36$ & 26 & $12-36$ \\
Number of patients & 6 & $2-20$ & 5.3 & $2-12$
\end{tabular}

Table 2 Student experience with appliances by dental school

\begin{tabular}{|c|c|c|c|c|c|c|c|c|}
\hline \multirow{3}{*}{ Type of appliance } & \multicolumn{8}{|c|}{ Amount of student experience } \\
\hline & \multicolumn{2}{|c|}{ None } & \multicolumn{2}{|c|}{ Moderate } & \multicolumn{2}{|c|}{ Extensive } & \multicolumn{2}{|c|}{ Total Schools } \\
\hline & 1994 & 1998 & 1994 & 1998 & 1994 & 1998 & 1994 & 1998 \\
\hline Removable & 0 & 0 & 8 & 11 & 2 & 2 & 10 & 13 \\
\hline Functional & 2 & 2 & 7 & 11 & 1 & 0 & 10 & 13 \\
\hline Single arch fixed & 3 & 2 & 7 & 11 & 0 & 0 & 10 & 13 \\
\hline Two arch fixed & - & 7 & - & 6 & - & 0 & - & 13 \\
\hline
\end{tabular}

Table 3 Estimates of student competence with different appliances

\begin{tabular}{|c|c|c|c|c|c|c|c|c|c|c|}
\hline \multirow{3}{*}{ Appliance type } & \multicolumn{8}{|c|}{ Estimated degree of student competence } & \multirow{2}{*}{\multicolumn{2}{|c|}{ Total Schools }} \\
\hline & \multicolumn{2}{|c|}{ Nil } & \multicolumn{2}{|c|}{ Incompetence } & \multicolumn{2}{|c|}{ Average } & \multicolumn{2}{|c|}{ Full } & & \\
\hline & 1994 & 1998 & 1994 & 1998 & 1994 & 1998 & 1994 & 1998 & & \\
\hline Removable & 0 & 0 & 1 & 1 & 5 & 11 & 4 & 1 & 10 & 13 \\
\hline Functional & 3 & 5 & 2 & 5 & 4 & 3 & 1 & 0 & 10 & 13 \\
\hline Single arch fixed & & 7 & & 5 & & 1 & & 0 & & 13 \\
\hline Twin arch fixed & & 13 & & 0 & & 0 & & 0 & & 13 \\
\hline
\end{tabular}

Table 4 Attitudes to the GDC recommendations, as defined in paragraph 95 of The First Five Years

\begin{tabular}{lccc}
\hline & Realistic & Unrealistic & Total schools \\
\hline $\begin{array}{l}\text { Students should be able to apply the principles of } \\
\text { orthodontics in general practice }\end{array}$ & 12 & 1 & 13 \\
$\begin{array}{l}\text { Students should recognise the limitations } \\
\text { that exist in general practice }\end{array}$ & 13 & 0 & 13 \\
& & & 13 \\
Students should be able to: & 12 & 10 & 13 \\
$\begin{array}{l}\text { Carry out diagnostic orthodontic procedures } \\
\text { Formulate treatment plans }\end{array}$ & 3 & 3 & 13 \\
$\begin{array}{l}\text { Relate plans to comprehensive patient care } \\
\text { Carry out continuing care of patients requiring } \\
\text { simple appliance therapy }\end{array}$ & 9 & 4 & 13
\end{tabular}

\section{RESULTS}

\section{Teaching practice survey}

There were 10 replies to the 1994 survey; all 13 schools replied in 1998. Curriculum hours devoted to orthodontics are shown in Table 1. Mean total course length was 195 hours, representing around 65 half days. However the range was from 109-286 hours so that the shortest course was less than half that of the longest. Courses ran from 1-3 years with a mean time span of 26 months.

It is not possible to make direct comparisons between all aspects of the 1994 and 1998 data since information concerning lectures was not obtained in the earlier survey. Time allocations for seminars and laboratory courses were similar for the two surveys although the amount of time spent by students in active clinical treatment had reduced by around 25\% over the 4 years between them.

There is much interest amongst UTG members concerning the use of Computer Aided Learning (CAL) programs. However only eight schools reported that CAL was available as part of the teaching programme and actual timetable allocation for the activity was low.
Table 5 Numbers of students in various ranges of scores for the results of the competency study

\begin{tabular}{cc}
\hline Score $(\%)$ & No. of students \\
\hline$<30$ & 3 \\
$31-50$ & 19 \\
$51-67$ & 36 \\
$68-83$ & 16 \\
Total & 74
\end{tabular}

The experience gained by students using appliances of various types appears in Table 2. All schools ran a programme in which students treated patients longitudinally. The average number of patients treated by each student was five, one less than reported in 1994. Perhaps the most interesting figure is that, in 1998, 85\% of schools claimed that students received moderate experience with single arch fixed appliances, whilst almost half of the schools claimed moderate experience with two-arch fixed appliances (Table 3).

In 1998 only one respondent claimed that students were fully competent in the use of any type of appliance, although all but one felt that students had average or better competence with removable appliances. Respondents were cautious concerning the competence of their students with fixed appliances (Table 4).

Five of the statements in the GDC document were supported by more than twothirds of course directors. However the suggestion that it was realistic to expect undergraduates to formulate orthodontic treatment plans received support from only three schools (Table 5).

\section{Competence study}

Replies were received from 12 out of the 13 UK dental schools, the total sample being 74 students. The average test score was $58 \%$ with a range of $14-83 \%$ (Table 5). School average scores ranged from 39-72\%.

Students performed with credit for basic knowledge questions but less well when they were required to apply that knowledge. Only around half of the students selected the correct teeth for extraction and the appropriate appliance type from a broad range of categories (Table 6).

\section{DISCUSSION}

\section{Teaching practice survey}

The results of this investigation reveal a great deal of variation in different undergraduate orthodontic programmes. This should not be surprising as the teachers of orthodontics in the UK are changing the focus of undergraduate education away from an attempt to teach compromise treatments with removable appliances. Instead the present aim is to provide infor- 
Table 6 Summary results from the competency study for questions grouped into five main categories

\begin{tabular}{lccc}
\hline & No. of questions & Average score $(\%)$ & Range $(\%)$ \\
\hline Basic knowledge & 5 & 71 & $38-86$ \\
Aetiology & 3 & 58 & $30-85$ \\
Diagnosis & 4 & 55 & $7-85$ \\
Extraction choices & 10 & 55 & $7-85$ \\
Appliance selection & 8 & 47 & $23-74$
\end{tabular}

mation on more relevant knowledge concerning the development and interception of malocclusion and when to refer patients for specialist orthodontic treatment. In a wish to expose dental students to contemporary standards of orthodontic care orthodontic teachers have begun increasingly to involve undergraduates in fixed appliance treatment so that they will be familiar with this when they encounter patients wearing fixed appliances in practice. However, despite an increasing tendency for students to receive some clinical experience with fixed appliances (Table 2), only one course director claimed that students had any degree of competence at the management of a fixed appliance (Table 3). In reality this experience may achieve little more than to inspire those who wish to pursue orthodontics at a postgraduate level.

One factor that may have influenced this change is evidence that has now accumulated on the relative effectiveness of orthodontic treatment mechanics. Although removable appliances may produce improved or greatly improved results in a high proportion of selected cases, ${ }^{2}$ most orthodontists would agree that fixed appliances are the more effective over the whole range of malocclusions. When considering whether it is possible to train undergraduates to use fixed appliances we should bear in mind that if a dentist wishes to satisfy the requirements for specialist training they must work as a specialist registrar in an approved full-time orthodontic post for 3 years. This is equivalent to around 5,000 hours of directed work within the hospital environment. In addition the graduate trainee must devote much additional time to study, essay writing and other activities related to the training programme. In sharp contrast the average time allocated to orthodontics in the undergraduate curriculum of a United Kingdom dental school is only 195 hours, representing around 65 half days. In that short time students are expected to acquire the ability to carry out diagnostic procedures, formulate treatment plans and relate them to comprehensive patient care. They are also expected to observe the complete treatment of some orthodontic cases. ${ }^{2}$ In three dental schools the overall length of the orthodontic course was 18 months or less and it is difficult to understand how this last requirement could be fulfilled in such a short time span. However there was broad support amongst academics for the GDC recommendations, except for the one concerning the formulation of treatment plans. This received support from only three schools.

\section{Competence study}

Results of the multiple choice examination used to test the orthodontic knowledge and treatment planning abilities of students revealed a wide range of competence between individual students and between students from different dental schools. No pass mark was set to indicate adequate competence since the objective was essentially one of information gathering. It could be argued that before qualification every student should be able to cope with any clinical situation that they encounter and therefore that only full competence is permissible. However the practice of clinical dentistry relies upon the common-sense of practitioners to refer for advice any patient about whom they feel uncertain.

In the present study questions requiring recall of factual information such as standard cephalometric values were answered reasonably well, although students at the lower end of the range did poorly, possibly because the topic was not taught in their dental school. However, once students were asked to apply knowledge and make clinical decisions their performance was less convincing and many failed to make structured treatment planning decisions. For example, the correct selection of extractions was often followed by an inappropriate choice of appliance.

\section{Overview}

The results presented here must be viewed against the current climate of orthodontic opinion in the United Kingdom. It has been suggested that only around 25\% of cases are suitable for treatment by extractions alone or with removable appliances ${ }^{3}$ and even then such treatment is unlikely to satisfy patients. ${ }^{4}$ It is likely that patient expectations have increased significantly in the last decade.

It has been reported that new graduates feel confident in most clinical fields but lack confidence in oral surgery, orthodon- tics, anaesthesia and sedation. ${ }^{5}$ Other studies have also reported that final year students lack the confidence to carry out orthodontic treatment. ${ }^{6,7}$ The present study provides evidence that these views are well founded with respect to orthodontic treatment planning, and supports earlier work which showed that a high proportion of GDP orthodontic treatment plans were found to be inappropriate when judged by orthodontic consultants. ${ }^{8,9}$

Only 45\% of general dental practitioners in England and Wales carry out any orthodontic treatment (Dental Practice Board, 1991). It follows that even those practices selected as suitable for vocational training may not provide a new graduate with additional supervised orthodontic experience. ${ }^{5}$ Formal general practitioner training programmes on the other hand have been shown to improve treatment standards. ${ }^{10}$ The truly crucial role of the general practitioner is in the recognition of malocclusion and where possible in the initiation of simple interceptive measures. However more than 50\% of GDPs refer all patients who require orthodontic treatment and a few appear to do so with little thought. ${ }^{11}$ Fox (1997) ${ }^{12}$ found that one practitioner accounted for $15 \%$ of his orthodontic waiting list at Hartlepool Hospital. If all GDPs followed this practice, specialist waiting lists would rise to unimaginable levels. At the present time as many as $46 \%$ of orthodontic referrals may be inappropriate. ${ }^{13}$ Attempts to remedy this problem by the production and dissemination of evidence-based referral guidelines have been shown to be unsuccessful, there being no difference in the proportions of appropriate referrals between dentists who received guidelines and those who did not. ${ }^{14}$ If it is accepted that the general practitioner is to continue to play a role in the provision of orthodontic care the authors believe:

- The orthodontic role of the general dental practitioner must be redefined with emphasis on the ability of the new graduate to carry out diagnostic procedures and recognise orthodontic problems which require treatment. This would move the UK more into line with European teaching. ${ }^{15,16}$

- Since it is evident that students lack the ability to plan orthodontic treatment, where the non specialist wishes to undertake this it should be to a prescription provided by a specialist unless that practitioner has received further training.

- Adequate opportunities should be provided for those general dental practitioners with a special interest in orthodontics to receive appropriate training 
in order to improve their knowledge and skills.

There should be moves towards establishing an appropriate geographical spread of trained orthodontic specialists to treat all but the simplest of cases.

The aims and objectives of the undergraduate orthodontic curriculum should be examined as a joint exercise between the University Teachers' Group of the British Orthodontic Society and the General Dental Council, as part of a review of The First Five Years.

1. General Dental Council. The First Five Years. The undergraduate dental curriculum. London: General Dental Council, 1997

2. Kerr W J S, McColl J H. Use of the PAR index in assessing the effectiveness of removable orthodontic appliances. Br J Orthod 1993; 20: 351-357.
3. Stephens C D, Harradine N W T. Changes in the complexity of orthodontic treatment for patients referred to a teaching hospital. Br J Orthod 1998; 15: 27-32.

4. Gravely J F. Who should practise orthodontics? Br J Orthod 1989; 16: 235-241.

5. Levine R S. Experience, skill and knowledge gained by newly qualified dentists during their first year of general practice. Br Dent J 1992; 172: 97-102.

6. Stephens C D. Orthodontic experience and clinica confidence of the recent graduate. BrDent J 1985: 159: 301-303.

7. Kay EJ, Blinkhorn A S. Scottish dental students views of their undergraduate training. Br Dent J 1987; 162: 317-319.

8. Stephens C D, Drage K D, Richmond S, Shaw W C, Roberts C T, Andrews M. Consultant opinion on orthodontic treatment plans devised by dental practitioners. A pilot study. J Dent 1993; 21: 355359.

9. Parfitt A A, Rock W P. Orthodontic treatment planning by general dental practitioners. Br J Orthod 1996; 23: 359-365.

10. Stratford N, Burden W. Clinical assistant training in orthodontics - How effective is it? Br Dent J 1998; 184: 448-452.

11. Hammond M, Evans D R, Rock W P. A study of letters between general dental practitioners and consultant orthodontists. Br Dent J 1996; 180: 259-262.

12. Fox N A. Audit of new patient referrals. Royal College of Surgeons of England Orthodontic Working Party 1997; Newsletter 10: 5.

13. Fox N A, Thompson R. Audit of new patient referrals. Royal College of Surgeons of England, Orthodontic Audit Working Party 1993; Newsletter 5: 6-7.

14. O'Brien K D, McComb J L, Fox N, Bearn D, Wright J. Do dentists refer orthodontic patients inappropriately? BrDent J 1996; 181: 132-136.

15. Myrberg N E A, Duterloo HS, Booy C, Van der Linden F P G M, Boersmay H, Prahl-Anderson B. Orthodontic services in the Netherlands; the standpoint of the Dutch Professors in orthodontics. Europ J Orthod 1986; 8: 65-66.

16. Adamides J P, Eaton K A, McDonald J P, Seeholzer $H$, Sieminska-Piekarczk B. A survey of undergraduate orthodontic education in 23 European countries. $\mathrm{Br} J$ Orthod 2000; 27: 84-91. 